\title{
Congestion Management Strategies of Real-Time Market
}

\author{
Qi Wang, Chunyu Zhang, Yi Ding \\ Center for Electric Power and Energy, Technical University of Denmark, Copenhagen, Denmark \\ Email: qiwa@elektro.dtu.dk, chzh@elektro.dtu.dk, yding@elektro.dtu.dk
}

Received December 2013

\begin{abstract}
The high penetration of distributed energy resources (DERs) will significantly challenge the power system operation and control due to their stochastic, intermittent, and fluctuation characteristics. This enhances the difficulty of congestion management of power systems in cross-border electricity market among different regions. For handling this, the Real-Time Market is proposed for balancing capacity trading against congestions. Several strategies for Real-Time Market dealing with congestions are proposed. The strategy of two-stage crossborder markets in Day-ahead, Intra-day and Real Time Market are introduced with the congestion constraints complied. Pre-Contingency strategy is proposed as the advance preparation for the future congestion, and In-Day re-dispatch is used for regulation. Accordingly, the requirements on facilities considering telemetry and remote control in a fast manner are discussed at last.
\end{abstract}

\section{Keywords}

\section{Congestion Management; Electricity Market; Real-Time Market; Distributed Energy Resources} (DERs)

\section{Introduction}

Heavy use of the electricity grid produces congestion, a situation in which the lowest-priced electricity can't flow freely to a specific area. In that case, the generations with more-expensive electricity price are ordered to meet the heavy demand. As a result, Locational Marginal Prices (LMPs) are higher on the receiving end of the congestion and lower on the sending end. Operating conditions such as fluctuating generations, intermittent great energy consumptions and transmission outages can cause congestion and result in electricity price changes $[1,2]$.

In recent years, due to the growth of energy consumption, the extensive use of conventional fossil fuels from the exhaustible resources and the environmental concerns, high penetration of distributed energy resources is considerably observed worldwide. However, the stochastic, intermittent, and fluctuation nature of the output from these resources are frequently discussed as a potential barrier to larger scale application of these technologies. In the future, energy grids, renewable, e.g. wind \& PV and more efficient energy sources, e.g. CHP are critical for improving the security of our energy supply by drawing upon sustainable natural sources and reducing environmental impacts [3,4]. However unlike conventional generation, high penetration levels of these 
DERs will pose a significant challenge associated with balancing of demand and supply, which may be a major cause of congestions in the future electricity grid [5,6].

DERs have already played an important role in many areas of Europe and American. For example, in Denmark, 30\% of the total electricity consumption comes from renewable energy, of which two third from wind power [7]. In the U.S., one gigawatt of solar power installed by May 2012, reflecting the rapid growth of solar power over the past few years [8]. By the end of 2012, wind power accounted for roughly $3.4 \%$ of installed capacity supply, which provided 12,634 GWh of annual energy in American [9]. Predictably, there will be more competition for these balancing resources and therefore these will result in a big probability of congestion occurrence.

In the current Nordic power market setup, the Crossborder Capacity Allocation in Intraday market is responsible for the equilibrium of supply and consumption against the congestions [10]. However, the U.S. runs a Real-Time Electricity Market where electricity price cleared in 5 minute intervals [11]. This Real-Time Market handles congestions by means of telemetry and remote control based on real time price signals [12]. In this paper, firstly analyzes the successful experience for congestion management in Nord Pool and PJM in U.S. Then several strategies for Real-Time Market dealing with congestions are proposed, including market strategies, constraints and operating strategies.

\section{Congestion Management of Nord Pool}

The Nordic Power market was the first international power market and it consists of four Nordic countries: Sweden, Finland, Norway and Denmark. These countries run a common power exchange, the Nord Pool, where market participants can buy and sell electricity [13]. The common power market was mainly motivated by efficiency reasons. The mix of production technologies in the Nordic power market is quite large and it would improve the efficiency of production if market participants could trade between countries. The main part of the production in Finland and Denmark is based on thermal generation, whereas Norway is a very hydro-intensive country. In Sweden, the electricity production is mainly based on hydro and nuclear power [14].

In the Nordic power market, the wholesale trade of electricity is organized through Nord Pool power exchange. The first settlement between energy supply and demand in a given hour of operation happens in the Day-ahead Market (DAM), which in the Nordic countries is called Elspot [15]. When the Elspot market closes, a price where the expected production meets the expected consumption is found. However, as the hour of operation approaches, this expected balance might need adjustment as the expectations regarding i.e. wind power production or consumption change. Therefore, a new settlement between production and consumption and production is found, first on the Elbas Intra-day Market (IDM) and then on the intra-hour regulating power market. The regulating power market is a common Nordic market for physical electricity trading 15 - 60 minutes prior to the hour of operation [16].

The Congestion management in Nord Pool is done in Intra-day Market, explicitly, the Intraday Capacity Service for Crossborder Capacity Allocation [17]. Available Transfer Capacity (ATC) plays the role as the cross border limits, combined with the given capacity constraints, within the time scope of one hour before regulation. The power flow is defined towards the higher price. After Elspot closes, transmission system operators (TSOs) allocate capacity on their own grid to Elbas where is a multi-area platform. The Physical Transmission Rights allocate through explicit auctions between border countries. These rights once nominated to the platform must be executed [10]. Figure 1 shows the Congestion Management Structure in Nord Pool.

\section{Congestion Management of PJM}

As a neutral, independent Regional Transmission Organization (RTO), PJM operates the wholesale electricity market of the 13 states of U.S. and Columbia District. PJM contributes to the most effective and cost efficient reliability of long-term high-voltage electricity grid for more than 51 million residents [18]. The continued increasing of renewable power generation, dominatingly wind and solar power, greatly enhances the opportunities to harness the unpredictable and intermittent uncertainties [19].

The wholesale electricity trading markets consist of several markets according to different time scale. The first settlement is cleared in Day-Ahead Electricity Market where hourly Locational Marginal Prices (LMPs) are calculated for the next operating day based on the balance of generation offers, demand bids and scheduled bilateral actions [20]. Instead of the traditional hourly Intraday Market, PJM adopts the Real-Time Market for the fast 
deviation correction just 5 minutes before dispatch [21]. Then for supporting the Real-Time Electricity Market, the Operating Reserve Market is designed for both Day-ahead and real-time operating reserves [22]. Otherwise, PJM has a Day-Ahead Scheduling Reserve Market, where supplemental 30-minute reserves are procured. It is the compensation mechanism to generators for providing reserve with day-ahead and balancing operating reserve credits.

In PJM, the Interconnection's LMP system takes account of congestion in determining wholesale electricity prices. It reflects the value of the energy at the specific location and the time it is delivered [23]. The LMPs send price signals that identify congestion, and encourage the development of new transmission facilities, new generations (e.g. DERs) or demand-response initiatives in areas where congestion is common [12]. Figure 2 shows the Congestion Management Structure in PJM.

\section{Congestion Management Strategies}

\subsection{Two-Stage Crossborder Markets Strategy}

In order to manage the congestion and pricing at the crossborder of the areas, two major strategies are adopted, one is minimum of Net Transfer Capacity (NTC), another is maximum of Available Transfer Capacity (ATC). They execute both in DAM, and IDM or Real-Time Market based on different time scope. The flow direction should be predefined in the DAM, for example, regard location A as reference connected with location B, the energy flow income to A defined as positive, on the contrary, the energy flow outcome from A defined as negative. For import positive flow, maximum the NTC into three levels, for example, $90 \%, 95 \%$, and $100 \%$ of the capacity. For export negative flow, set one level of minimum ATC. The flow direction defines should be done respectively by both of the connected two location A and B. The NTC and ATC calculations are performed separately by both A and B. Due to the different calculation formulas which vary with respect to the flow direction, monthly or yearly nomination summation, A and B may get different value of NTC and ATC. The final value should be decided by the matching of the values from A and B. the values should be not always equal, TSOs can determine where can be inconsistency according to their own crossborder nominations.

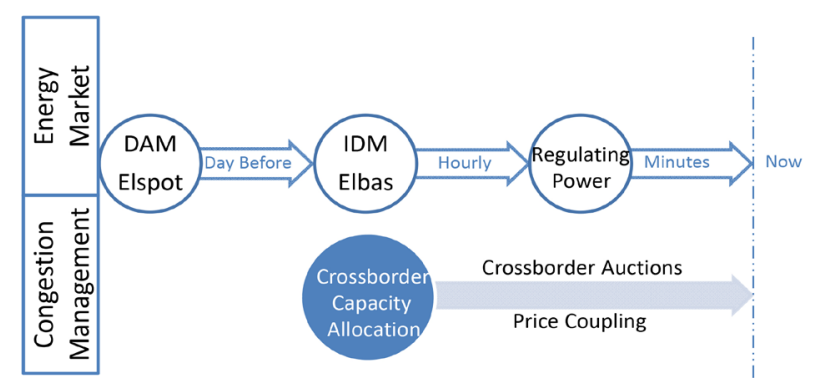

Figure 1. Congestion management in Nord Pool.

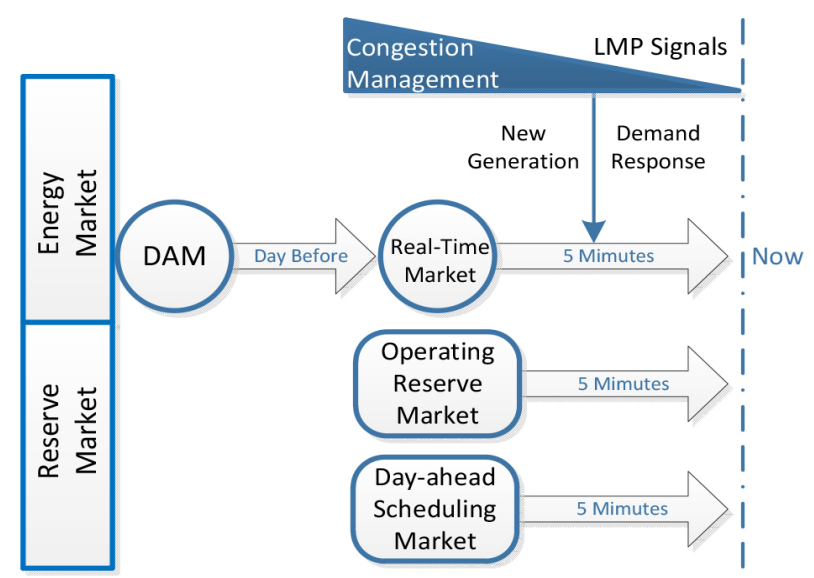

Figure 2. Congestion management in PJM. 
The calculation is performed in two stages, in DAM and IDM respectively. In DAM, the calculation firstly execute on Day-2 by TSOs to provide 24 NTCs for their own borders; then these NTCs are shared among all TSOs and matched centrally to determine an equal value; finally, each TSO verifies and adjusts their own optimal value corresponding to each security constraints. After confirming each NTC value, the capacity on borders is allocated through an auction by price coupling subject to crossborder flows, orders' acceptance and rejection. Consequently, the pricing may result in two probabilities:

- If the borders capacities are sufficient, the electricity prices among all the borders are the same;

- If the capacities are insufficient, the prices are different.

In DIM, the same calculation and matching occur but in intraday time scale. The calculation firstly happen in Day-1 afternoon after DAM closed. Then the joint auctions are performed in separate energy blocks for every individual hour of the day. The NTC values are recalculated refer to the intraday constraints and adjust the deviation of the DAM results. On all the borders, there may be several intra-day allocation gates per day. The prices may be the same or different depending on the sufficiency of the border capacities.

For Real-Time Market, the NTC calculation and matching are even faster to five minutes just before dispatch. The joint auction and price coupling are depending on the information signals from telemetry and for remote automatic control. The fast performance is valuable for integrating unpredictable DERs and demand response participant as reducing consumptions.

\subsection{Congestion Constraints Strategy}

The calculation of NTC and ATC must comply with special constraints for congestion management. The Australian Energy Market Operator (AEMO) operates a real time, security-constrained, economic fast dispatch energy market, where we may extract a lot of valuable experience from [24]. The constraints are illustrated as follows:

- The equations should follow the binding constraints. Binding is not only the summation of a certain time, but also the collection of several functions. For example, the frequency control requirement, or the networks support for the same generators.

- The constraints need consideration of power market impacts. The market impact is the re-run mechanism by the marginal values subject to the marginal constraint cost. This market impact is large on the bidding of the individual generator.

- The interconnector limits should include in the constraints. Constraint equations set the import or export limit for an interconnector at a particular time with consideration of the impacts from multiple interconnectors, frequency control requirements and generators production.

- Transmission outage times should be submitted before the start time of the outage, and then be rescheduled.

- Demand forecast deviation may impact the line rating a lot. Therefore, Demand forecasting need have the potential to forecast dynamic line ratings for the reasonable pre-dispatch.

\subsection{Pre-Contingency Basis Strategy}

Pre-Contingency strategy for congestion management is based on the off-cost generations which run to alleviate contingency overloads. The basic idea is to find ample fast-start generation or switching actions available for eliminating the actual overload caused a contingency. The facilities must have more than one fast-start combustion turbine or diesel generator in the vicinity or off-line.

In case of the possibility that some generation will not start, normally, $120 \%$ availability of generation is fit for establishing a short-term emergency rating for 30 minutes. The Transmission Owner (TO) may offer generation run-back schemes and switching and reclosing procedures to control these facilities. Local Control Centers (LCC) must be capable of implementing the Pre-contingency switching procedures via SCADA control. Additionally, LCCs must also have the ability to dump sufficient load via SCADA in the event that switching procedures cannot be implemented, for example, pre-contract for load shedding with large electricity consumers.

\subsection{In-Day Congestion Strategy}

Besides the Pre-contingency strategy as the preparation for avoiding congestion in advance, the operations and dispatches should be considered in case if In-Day Congestion happens out of forecasting. In In-Day Congestion 
case, TSOs and Dispatchers should maintain the actual flow within $+/-100$ MWs of their Desired Flows by the following operations,

- Coordinate Phase Angle Regulators to adjust the desired flows within predefined thresholds. It can adjust flows moving from the one line to other lines that the adjustment does not exceed a certain MW for not increase total transmission cost.

- The adjustment should be notified by a phone call and recorded in information systems.

- Curtail all the market transactions that are not willing to pay congestion.

- Rebalance the flows back within the certain MW bandwidth. If the rebalance is not achievable, confirm a Desired Flow Offset.

- Re-dispatch the confirmed flow.

\subsection{Consideration on Facilities Requirements}

In order to control loading and voltage with fast activations, all facilities under congestion management must be observed in by TSOs through sufficient telemetry to provide accurate and reliable state estimation, with requirement of some redundant metering. The facilities for a line or transformer must be observable with sufficient telemetry redundancy. The branch has MW/MVAR telemetry at both ends and there is some MW/MVAR telemetry for other branches injections at buses connecting to the branch. The bus has at least one voltage telemetry point and it also has some MW/MVAR telemetry for its branches and injections. Figure 3 shows the comprehensive concept of Congestion Management Strategies in Real-Time Market.

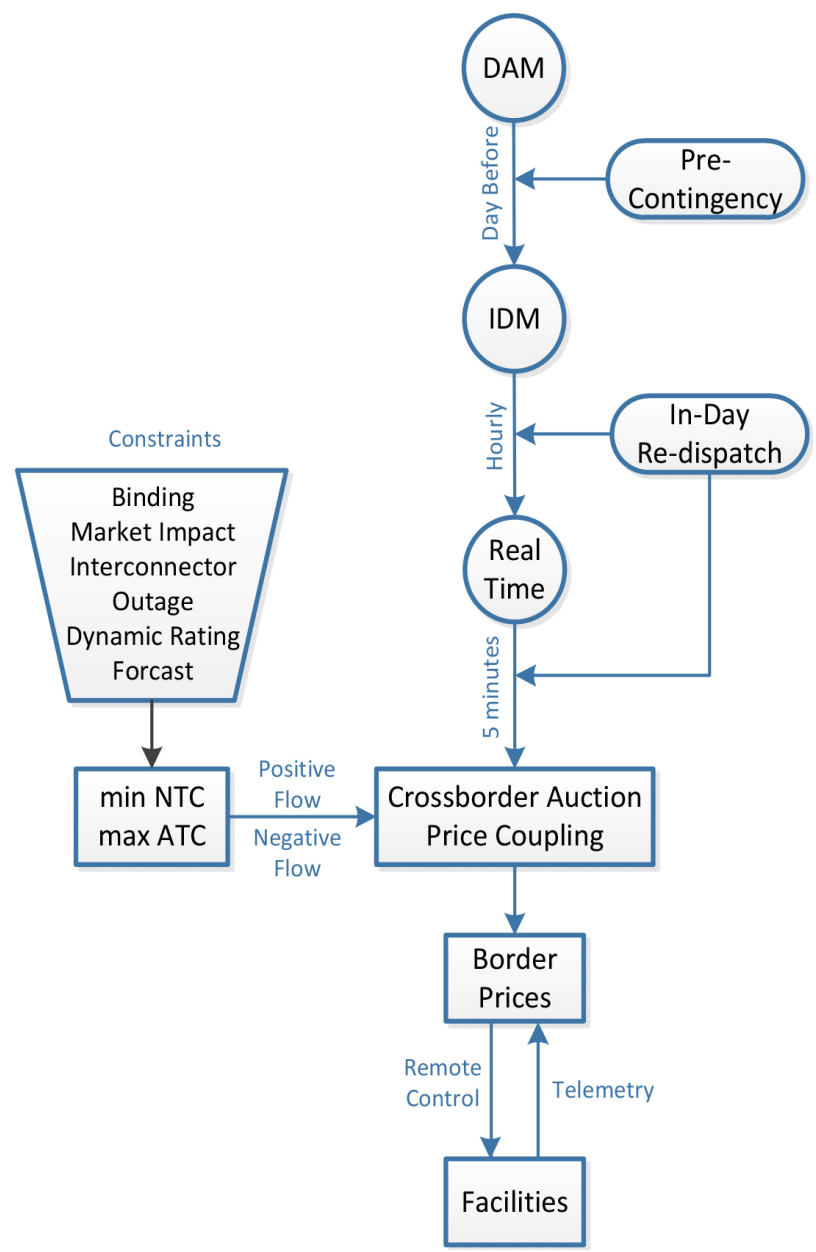

Figure 3. Concept of congestion management strategies in real-time market. 


\section{Conclusion}

This paper focuses on the strategies for congestion management of Real-Time Electricity Market. After the analysis of the congestion management experience both in Nord Pool and PJM in the U.S., five strategies are proposed from the perspectives of electricity market design. The strategy of two-stage cross-border market implements the auctions for congestion alleviating in the first stage (Day-ahead), and the second stage in Intra-day and Real Time Market. The constraints especially for congestion calculation are discussed as well. While, the pre-Contingency strategy is the advance preparation for the future congestion, when congestion occurs, it is solved by In-Day re-dispatch. Finally, the requirements on facilities for telemetry and remote control in a fast manner are discussed.

\section{References}

[1] Dan, C., Stefan, K. and Constantin, B. (2010) Deregulated Power Market Congestion Management. Proceedings of the 15th IEEE Mediterranean Electrotechnical Conference, Melecon, 654-659.

[2] (2011) Communication from the commission to the European Parliament, the Council, the European Economic and Social Committee and the Committee of the Regions, Smart Grids: From Innovation to Deployment, Brussels.

[3] Zhang, C., Ding, Y., Jacob, Ø., et al. (2013) A Flex-Market Design for Flexibility Services through DERs. Proceedings of IEEE ISGT Europe 2013, Copenhagen, 6-9 October 2013.

[4] Ding, Y., Pineda, S., Nyeng, P. and Jacob, Ø. (2013) Real-Time Market Concept Architecture for EcoGrid EU-A Prototype for European Smart Grids. IEEE Transactions on Smart Grid, 4, 2006-2016.

[5] Zhang, C., Ding, Y. and Li, Y. (2013) New Organizations in Electricity Market. Flex Power Project Report, Copenhagen.

[6] Zhang, C., Ding, Y., Jacob, Ø. and Wu, Q. (2013) Generation Expansion Planning Considering Integrating Large-Scale Wind Generation. Proceedings of IEEE IECON 2013, Vienna, 10-13 November 2013, 2049-2054.

[7] (2012) Master Data Register for Wind Turbines. http://www.ens.dk/da-DK/Info/TalOgKort/Statistik_og_noegletal/Oversigt_over_energisektoren/Stamdataregister_vind moeller/Sider/forside.aspx

[8] PJM (2012) Solar Power. http://www.pjm.com/about-pjm/renewable-dashboard/solar-power.aspx

[9] Fagan, B., Luckow, P. and White, D. (2013) The Net Benefits of Increased Wind Power in PJM. http://www.synapse-energy.com/Downloads/SynapseReport.2013-05.EFC.Increased-Wind-Power-in-PJM.12-062.pdf

[10] Barquín, J., Rouco, L. and Rivero, E. (2011) Current Designs and Expected Evolutions of Day-Ahead, Intra-Day and Balancing Market/Mechanisms in Europe. http://www.optimate-platform.eu/downloads/index.html

[11] PJM (2013) Real-Time Energy Market. http://www.pjm.com/markets-and-operations/energy/real-time.aspx

[12] PJM Operations Support Division, Transmission Operations Department (2013) PJM Manual 03: Transimission Operations. http://www.pjm.com/ /media/documents/manuals/m03.ashx

[13] Nord Pool (2005) Conversion of Block Bids and Use of Flexible Hourly Bids. Exchange Information, No.81.

[14] Nord Pool ASA (2004) Trade at the Nordic Market. Nord Pool Power Exchange.

[15] Nord Pool (2013) System Price. http://www.nordpool.com/How-does-it-work/Day-ahead-market-El-/Price-calculation/

[16] The Nordel Market Development Group (2008) Description of Balance Regulation in the Nordic Countries.

[17] Nord Pool (2006) Implementation of Annex to Regulation EC 1228/2003 (Congestion Management Guidelines) in the Nordic Electricity Market. http://www.nordpoolspot.com/Documents/Exchange\%20Information/EnclEIno78.pdf

[18] PJM Interconnection (2013) PJM’s Response to the 2012 State of the Market Report.

[19] PJM (2013)A Greener Grid.

[20] Shoemaker, J. (2012) Current PJM Real-Time Data Exchange. PJM.

[21] PJM (2014) Real-Time Energy Market. http://www.pjm.com/markets-and-operations/energy/Real-Time.aspx

[22] PJM (2012) Market Participant Process Improvements.

[23] Bowe, T.T., Mallinger, T., Rodriquez, A.J. and Zwergel, D. (2004) PJM-MISO Congestion Management Process. Power Systems Conference and Exposition, IEEE PES, vol. 3.

[24] AEMO Congestion Modelling (2013) The Nem Constraint Report 2012. Document REF: SC_CM_30, Version: 2. 